fatally as the prognosis in these cases is always grave. I think the quick evacuation of the fluid in the bullæ and the antiseptic treatment applied locally and con tinued afterwards were the means of cntting short the attack and so saved the life of the infant. What I could not understand and had never seen before was the very complete exfoliation of the outer cuticle over the entire body, which on healing again left the skin perfectly clean and free from any blemish. This case was seen by a brother practitioner, who at once diagnosed it as pemphigus and gave his opinion that it must be due to syphilis and would probably end fatally. This, I am glad to say, was not the case and the infant up to the present time is perfectly well and has never had the slightest return of any rash or symptom, neither does he show any of the characteristics of inherited syphilis.

Cheyne-gardens, S.W.

\section{A FEW CASES OF ETHYL GHLORIDE NARCOSIS.}

BY.W. J. MC CARDIE, B.A., M.B., B.C. OANTAB., AN ASTHETIST TO THFi GENERAL AND DENTAL HOSPITALS, BIRMINGHAM.

KTHYL chloride, according to Kappeler, was first tried as an anæsthetic for surgical operations by Heyfelder. Recently Lotheissen of Innsbruck introduced it for general use in minor, or comparatively minor, surgery with great success. Ludwig and Wiesner and others quickly followed suit, and now some thousands of cases have been recorded. Occasionally it has been administered for 30 , and once for 55, minutes for operations like colotomy and amputation, and in many of the shorter gynæcological interventions.

Ethyl chloride is said to have many advantages and few disadvantages. Anæsthesia is quickly (in about two minutes) induced and as rapidly passes off, leaving no, or slight, after-effects, has no irritating action, and can be administered in heart, lung, or kidney diseases where ether and chloroform are contra-indicated or dangerous. Its main disadvantage is that, except perhaps in children, muscular relaxation is generally not complete and rigidity may be marked in muscular, and especially in alcoholic, subjects.

The best mask to administer from is tbat of Breuer, to be obtained in Vienna, a close-fitting one with inspiratory and expiratory valves and a chamber above the former to hold the gauze on which the drug is to be sprayed. Large graduated flasks containing 50 cubic centimetres and a freer spraying capacity than usual should be used, so that the usual dose of from five to six cubic centimetres can be quickly poured out. The whole apparatus is very portable and convenient. Before I tried ethyl chloride on others I asked Mr. Charles St. Johnston, M.R.O.S., to administer it to me experimentally in a dental chair, and I can say that the subjective effects were like those of nitrous oxide in every respect and not at all unpleasant. Lotheissen has collected 2500 cases with one death, that of an extremely bad subject. Complications during the induction or continuance of anæsthesia appear to be rare, chiefly, so far as I can read, of an asphyxial kind and dependent on some mechanical factor.

Ethyl chloride would seem to be increasingly used in Germany and France, like ethyl bromide, in operations for which nitrous oxide alone, or mixed with oxygen, would be, if possible, administered in England.

The following are short notes of my first 10 cases, the first two on Jan. 15th of this year.

1.-A woman, aged 40 years; extraction of three teeth. Anæsthesia was irduced in two and a half minutes and lasted about one minute, passing off quietly. The colour was heightened throughout. The inhaler was removed before the conjunctival reflex was abolished; there was very slight phonation towards the end, but there were perfect anæsthesia and recovery.

2.-A woman, aged 21 years ; extraction of three teeth. The course was much the same as in the last patient, the pulse being gocd and regular during the operation; there was no excitement or muscular spasm. The patient seemed to be in an analgetic condition.

3.-A woman, aged 24 years. It took three minutes to get her apparently onder-i.e., just stopping short of abolition of conjunctival $r \in f \in X$-but recovery was so rapid (a quarter of a minute) that no extraction could be performed. $\mathrm{N}_{2} \mathrm{O}$ was therefore administered and two teeth were removed.

4.-A strongly-built woman, aged 20 years; tooth extraction. After three minutes' inhalation with little apparent effect, I changed to $\mathrm{N}_{2} \mathrm{O}$ to complete the operation.

In the above cases I was proceeding very carefully because the exhibition of the drug was new to me and in Cases 3 and 4 too little was administered. Again, I was not using a graduated flask and so did not know how much ethyl chloride was sprayed on.

5. - A man, aged 26 years; a difficult extraction. He was the ordinary type of patient. There was good anæsthesia from 20 to 35 seconds. There was no excitement; the colour and respiration were good. Administration was stopped when the conjunctival reflex became much dulled.

6.-A woman, aged 23 years; extraction of two teeth. She was under (the reflex was not gone) in about two minutes. 30 seconds of quiet anæsthesia were obtained; about five cubic centimetres were used. The patient felt a little giddy for a short time afterwards.

7.-A woman, aged 18 years; extraction of six teeth. The patient was very nervous, thin, and had a high arched palate. She felt sick and retched during the taking of an impression of the mouth before operation. There was quiet induction in two minutes; the reflex was just lost, the eyes were turned in, and the pupils were well contracted; the colour was good; the respirations were slow and regular. Perfect anæsthesia for more than one minute was obtained. The recovery was very gradual and quiet; two or three more teeth could have been extracted. She then retched much and vomited a little for a few minutes. She afterwards said that she felt well and much better than after $\mathrm{N}_{2} \mathrm{O}$ on two previous occasions.

The usual dental sitting-up posture was kept in all these cases.

8. - A girl, aged eight years; tonsils and adenoids. The administration was slow. Anxesthesia lasted for 25 seconds. Reapplied for tonsils; anæsthesia lasted for 20 seconds. Recovery was as perfect and rapid as from $\mathrm{N}_{2} \mathrm{O}$. There was no change of colour throughout.

9.-A boy, aged 12 years; tonsils and adenoids. The course was the same as in the last case, only the anæsthesia was much shorter.

10.-A spare woman, aged 32 years; scraping, \&c., grantalations of both ears. From five to six cubic cent metres were sprayed on the inhaler. There was quiet induction in three minutes; the conjunctival $r \in$ flex was just lost. There was perfect anæesthesia with slight muscular rigidity throughout which did not inconvenience the operator. The colour, pulse, and respiration were very good. Reflez was present most of the time corresponding to moderately contracted pupil. The reflex was twice abolished when the pupil became well contracted and breathing became a little slower. Complete recovery occurred in about one and a balf minntes. Operative an esthesia lasted for frve minutes. The patient vomited a little bile-stained fluid shortly after being put to bed. She then felt well, but five hours later she complained of feeling faint for a short time. She was quite well the next day. This was a most successful case in every way.

I used Breuer's mask for all these patients and found it very convenient to manipulate. At no time had I anxiety, nor did I see any change for the worse either in respiration or circulation. I have several times used ethyl chloride instead of nitrous oxide as a preliminary to etherisation and with the same successful effect. The few cases which $I$ have briefly and imperfectly recorded have been so successful that I shall lose no suitable opportunity of testing the drug in carefully selected patients for longer and more difficult operations.

Birmingham.

\section{A FURTHER NOTE ON THE PRODUCTION OF LOCAL AN ÆSTHESIA IN THE EAR, NOSE, AND THROAT. BY ALBERT A. GRAY, M.D., F.F.P.S. GLASG., \\ AURAT SURGHON TO THE GIASGOW CENTRAL DISPENSARY.}

IN The LANCET of April 21st, 1900, p. 1125, I described a method by means of which the difficulty of obtaining local anæsthesia in the ear could be overcome. It consisted essentially in using a solntion of cocaine in anilin oil and rectified spirit. I further mentioned the limits within which 
that method was applicable. As the method has been widely adopted both in this country and abread I propose to describe some little improvements I have been able to make which allow the limits of its application to be considerably widened. Several correspondents wrote to me asking " what is anilin oil ?" as they had not been able to obtain it at the druggists, nor could they find the name in works on chemistry. In reply to these inquirers I have only to say that anilin oil is the same as anilin. It is the French huile d'anilin and the German anilinöl. It is, of course, not an oil at all, but is frequently termed such because of its oily consistence. When fresh it is almost colourless, but it turns yellow or brown with time. It should be kept in a glass-stoppered bottle and in a dark place.

In the paper referred to I described the method I then employed, using simply a 10 per cent. solution of cocaine hydrochlorate in a mixture of equal parts of anilin oil and rectified spirit. For ear work this proved highly satisfactory, but for operations involving deeper parts, such as excision of tonsils, the removal of bony spurs from the nasal septum, \&c., although much better than the simple aqueous solutions of cocaine it still did not completely annul the pain and, moreover, caused a burning sensation. The most obvious way to accomplish this end was to make the solution stronger, and this was what I did. To avoid the dangers of using strong solutions of cocaine, I mixed $\beta$-eucaine ${ }^{1}$ with the cocaine in the following way. Two solutions were made: (1) a 20 per cent. solution of cocaine hydrochlorate in rectified spirit; and (2) a 15 to 20 per cent. solution of eucaine in anilin oil. The latter is not a true solution, however, as eucaine is only soluble to about the extent of 10 per cent. in anilin oil ; a proportion of the eucaine, therefore, lies at the bottom of the bottle. Before use the bottle containing solution No. 2 is well shaken up and 10 minims (measured) are ponred out; to this are added 10 minims of No. 1 solution and the mixture becomes clear in a few seconds. This gives the following formula: cociane hydrochlorate 10 parts, $\beta$-eucaine 10 parts, anilin 50 parts, and rectified spirit 50 parts. Of course this solution may be kept in stock, but it turns brown very soon and arpears to a slight extent to lose its highly penetrating quality. I therefore keep the solutions separate until just before use, though perhaps the precaution is unnecessary. With this solution I have been able to dispense with all aqueous solutions of cocaine in ear and throat work.

The method of use is different according to the region in which the anæesthesia is desired. In the ear the method I formerly employed was to pour the solution into the meatus while the head was turned to one side. I frequently employ this method still, but another equally efficacious way was suggested to me by Dr. Arthur Hutchison-viz., to soak a small strip of ganze with the solution and to push it down the meatus through the speculum to the required depth. This method certainly diminishes the amount of cocaine and anilin oil absorbed.

In my previous communication I stated that the method was not suitable for throat and nose work on account of the burning pain which it temporarily caused. Further experience has led me to change my opinion in this respect, as I find that the disagreeableness of the burning sensation is fully compensated for by the much deeper anæsthesia obtained and the freedom from symptoms of cocaine intoxication. The method which I employ in throat and nose work is as follows. 10 minims (measured) of the eucaineanilin solution are poured out and 10 minims of the cocainespirit solution are mixed with them. The mixture, at first opaque, becomes clear and consists of a 10 per cent. solution of cocaine and 10 per cent. of eucaine. Under no circumstances do I use more than 20 minims of this solution-that is to say, 10 minims of anilin. That amount is quite sufficient for the painless excision of tonsils, removal of spurs on the septum, cauterising, and other operations. In applying the solution the anæsthetic effect appears to be considerably enhanced if it be rubbed gently over the part for a few seconds. This is done by saturating a small pledget of cotton-wool at the end of a probe with a few minims of the solation and rubbing it in. A period of at least seven minutes should then be allowed to elapse, at the end of which the anæsthesia will be found to be complete; much more so than that obtained by much larger quantities or stronger aqueous solutions of the anæsthetics. It should be

On the Use of Fucaine in Otolog 7 and Laryngology see a paper by Yearsley and Horne, Brit. Med. Jour., Jan. 16th, 1857 . added that if, after producing anæsthesia, chromic acid be used as an escharotic, the scab will be dark green in colour owing to the formation of an anilin dye. This produces no deleterious effect in the system and does not diminish the efficacy of the caustic.

In regard to the physiological effects of this method a few words are required. I have not bad any trouble myself with symptoms of intoxication, either by the anilin or by the cocaine. I have, however, heard of two cases in which a little trouble resulted. Of one of these I am nnable to give details as it was reported to me by a third person. It was a case evidently of cocaine intoxication and the patient recovered in the course of an hour or two. The second case occursed in a patient, aged six years. The solution was instilled into the meatus until the latter was full. In the course of an hour or so the patient's lips became blue and slight gastric catarrh occurred, but no other symptoms were present and the patient was well again in a few hours. As a matter of fact. beyond the peculiar blue colour of the lips there was nothing alarming to note. Excepting these cases, neither of which occurred in my own practice, I have not seen or heard of any trouble with the solution. On the other hand, I never have now any of those symptoms of cocaine intoxication with which rhinologists are so familiar when the aqueous solution is applied to the nasal mucous membrane, and which, though not usually alarming, are yet sufficient to prevent the carrying out of minor operations, much to the chagrin of the surgeon and the patient. Using the solutions in the manner described above excludes these extremely disagreeable symptoms.

A few words may be said in regard to the peculiar blue colour of the lips which sometimes occurs. Several of my patients have told me that an hour or two after the use of the solution their friends noticed this peculiar colour. No symptoms were present in any of the cases and the patients would not have known about it had their attention not been drawn to it by their friends. It always passes off in the course of a few hours and leaves no effects. Professor Stockman informs me that this is due to the transformation of oxyhæmoglobin into methæmoglobin. Its occurrence may be avoided if so desired by limiting the dose to 20 minims for adults or adolescents and corresponding doses for children. As regards children it must be remembered that they are said to stand cocaine badly. For my own part I have not seen any objectionable symptoms in children, but then I have always been careful about using cocaine in any form in these patients. Glasgow.

\section{TWO CASES ILLUSTRATING THE USE OF THE X RAYS IN SURGERY.}

BY G. P. NEWBOLT, F.R.C.S. ENG.,

HONORARY SURGEON TO THE ROYAL SOUTHERN HOSPITAL, IIVERPOOT; AND

C. THURSTAN HOLLAND, M.R.O.S. KNG., L.R.C.P. LOND.,

HONORARY MEDICAL OFFICER IN CHARGE OF THE X-RAY DEPARTMENT ROYAL SOUTHERN HOSPITAI, IIVERPOOL.

CASE 1.-The patient was a boy, aged 18 years, who was shot in the face. On August 28th whilst lying down another boy pointed a revolver into his face and it accidentally went off. The left eye being injured he was taken to the Liverpool Eye and Ear Infirmary where the eye was removed on the following day by the honorary surgeon, Mr. C. G. Lee. The bullet was not found in the eye, and on August 30 th an $\mathrm{x}$-ray examination was made by $\mathrm{Mr}$. Holland. The boy lying down on his left side, two wires were fixed at right angles to one another across the left side of the face, and the skiagram shown in Fig. 1 was obtained. The apparatus used was a 10-inch coil worked with accumulators and the exposure was 90 seconds. The wound of entrance was at the left side of the bridge of the nose, just internal to the angle of the eyelids. The bullet had passed through the left eye and across the superior maxilla, leaving small pieces of lead in different parts on its way along. The spot under which the bullet lay was, from the x-ray examination, given as follows: draw a line straight forward from the lower margin of the lobe of the left ear and measure one inch from 